\title{
Morphological and molecular identification of Beauveria bassiana from agricultural soils
}

\author{
Norjmaa U.*, Nasandulam D., Enkhjargal B., Banzragch D. \\ School of Agroecology, Mongolian University of Life Sciences, Ulaanbaatar, Mongolia \\ *Corresponding author: norjmaa@muls.edu.mn
}

\begin{abstract}
The soil environment is an important reservoir for a wide variety of entomopathogenic fungi, which can significantly contribute to the control of insect populations, especially on agricultural pests. Comparison of entomopathogens with conventional chemical pesticides, there are advantages in using biological control agents, such as human safety and other non-target organisms; pesticide residues are minimized in food and biodiversity increased in managed ecosystems. The main objective of this study is to detect and identify the entomopathogenic fungi from agriculture soils based on morphological and molecular identification. Total of 115 soil samples were collected in spring (before sowing) from different crop fields in "Unjin" and "Nart" Research and Education Centers of the university, which are located in Bornuur sum, Tuv Province from 2016 to 2018. Isolation of entomopathogenic fungus, Beauveria bassiana was isolated using Dilution plate method in Peptone Dextrose Agar Yeast. Based on microscopic observation, hyphae branched and formed conidiogene cells, and single cell B. Bassiana conidium was round and tend to oval with hyaline color. Colonies on PDAY were white to pale yellow and sometimes red pigments in reverse. Using PCR method with primer specific for identification B. bassiana, molecular analysis confirmed that all six isolates has same size of band which, appeared on agarose gel.
\end{abstract}

KEYWORD: Insect, crop rotation, entomopathogenic fungi, PCR

\section{INTRODUCTION}

Over few decades, synthetic chemical pesticides have been mainly used for pest control. However, their effects on non-target organisms, residues on crops, pest resistance and concern over the environmental impact of agricultural inputs give urgency to the search for an alternative, biologically based forms of pest control [1]. Interests in microbial insecticides as biological control between 1980 and 1990, usage and safety aspects are discussed more detail in publications by Hall et al. [2] and Laird et al. [3]. As seen the advantages in using microbial control agents, the importance of entomopathogens has been highlighted as an environmentally friendly pest control method [4].

Approximately 750 species of entomopathogenic fungi are known from 85 genera found throughout the classes of fungi [4]. Most of the taxonomic groups contain entomopathogenic genera, such as Metarhizium, Beauveria, Verticillium, Nomuraea, Entomophthora, and Neozygites, and few others. One of the best-known genera of entomopathogenic fungi is Beauveria bassiana, which isused for biological control of insect pests.

Generally, the main difference between the most common species of entomopathogenic fungus has been characterized based on their shape and size of colony and conidia. However, it is still problematic due to the relatively large heterogenicity of spherical B. bassiana. Conidial morphology and development criteria are commonly used to identify and classify genus level as Beauveria spp. Due to these difficulties on morphological identification a molecular technique was developed to assist complementary identification of the fungus [5].

There are few studies have been done on entomopathogenic fungus $B$. bassiana, as well as determination of biological activity for Metarhizium anisopliae [6]. In Mongolia, local strains of fungus $B$. bassiana $\mathrm{Bb}-\mathrm{G} 07$ and $\mathrm{Bb}-\mathrm{G} 10$ has been isolated from naturally infected locusts in 2011 [7].

Soil is the main source and natural habitat for entomopathogenic fungi [8]. Hence, the main goal of thepresent study is to detect and identify the entomopathogenic fungi B. bassiana in agricultural soils with different crops based on morphological and molecular identification. In this study, molecular analysis with multiplex PCR in order to confirm the result of morphological identification has been performed. 


\section{MATERIALS AND METHODS}

A total of 115 soil samples were collected between 2016-2018 from different crop fields in "Unjin" and "Nart" Research and Education Centers of the university, which are located in Bornuur sum, Tuv Province, Mongolia. In each sampling site, soil samples $(1.5-2 \mathrm{~kg})$ were collected from selected 5 points of $0-20 \mathrm{~cm}$ in soil depth. Sub-soil samples were mixed together to make it homogeneous. Then, the soil was sieved and stored at $4^{\circ} \mathrm{C}$ in the dark before use.

Isolation and morphological examination have been done at the Laboratory of Plant diseases, School of Agroecology, Mongolian University of Life Sciences. Molecular identification of PCR analysis has been done in Genetic Laboratory of Seoul University, South Korea. For the B.bassiana, it was isolated using dilution plate method in Potato Dextrose Agar Yeast (PDAY). At first, isolation of B.bassiana was identified based on their morphological characterizations. Morphological characters of the colonies include the growth pattern, color, shape, surface texture, colony elevation, and time that colony needed to cover up the petri dish Microscopic observations of $B$. bassiana were characterized such as shape, color of hyphae and conidia as referred by Kulu et al [1].

\section{RESULTS AND DISCUSSION}

\section{Morphological identification of $\boldsymbol{B}$. bassiana}

$B$. bassianawere isolated from 6 isolates among 570 samples fromsoils in fruit, vegetables and wheat
Genomic DNA was extracted with the established CTAB method [9]. Briefly, cell walls of fungal mycelia were broken down by grinding with glass rods or in the presence of liquid nitrogen. The CTAB extraction buffer was then added, and after incubation at $65^{\circ} \mathrm{C}$ purification with phenol: chloroform:isoamyl alcohol (25:24:1) and precipitation with isopropanol were conducted. Finally, the DNA was dissolved in $50 \mu \mathrm{l}$ of pure water.

To confirm the identity of the causal fungus, the complete ITS rDNA of the representative fungal pathogen was amplified and sequenced using primers ITS1 (5'-TCCGTAGGTGAACCTGCGG-3') and ITS4 (5'-TCCTCCGCTTATTGATATGC-3') as described by White et al. [10].

PCR reaction mixture (totally $50 \mu \mathrm{l}$ ) was consisted of $1 \mu \mathrm{l}$ from of dNTPs mixture, $1 \mu \mathrm{l}$ of each 2 primers, $25 \mu \mathrm{l}$ Green Taq master mix (all from AB gene), $3 \mu 1$ of genomic DNA and $19 \mu \mathrm{l}$ pure water. The My Genie $^{\mathrm{TM}} 32$ Thermal Block, Bioneer was programmed as follows: $5 \mathrm{~min}$ at $95^{\circ} \mathrm{C}$ for initial denaturation; 35 cycles of denaturation for $35 \mathrm{~s}$ at $94^{\circ} \mathrm{C}$, annealing for $30 \mathrm{~s}$ at $58^{\circ} \mathrm{C}$, extension for $30 \mathrm{~s}$ at $72^{\circ} \mathrm{C}$; and a final extension for $10 \mathrm{~min}$ at $72^{\circ} \mathrm{C}$.

fields of Bornuur sum. Morphological characterization of $B$. bassianaisolates are shown on Table 1.

Morphological characters of Beauveria bassiana isolations

Table 1.

\begin{tabular}{lllllll}
\hline \multirow{2}{*}{ Isolate code } & Sample location & \multicolumn{5}{c}{ Colony Observation } \\
\cline { 3 - 6 } & & $\begin{array}{l}\text { Growth } \\
\text { pattern }\end{array}$ & Color & Shape & Texture & Elevation \\
\hline B.b & $/ \mathrm{N} /$ Wheat field* & $\begin{array}{l}\text { Disperse } \\
\mathrm{Bu}\end{array}$ & White & Round & Smooth & Raised \\
$1-1-3$ & $/ \mathrm{U} /$ Potato field & $\begin{array}{l}\text { Disperse and } \\
\text { dense }\end{array}$ & White & Round & Smooth & Raised \\
$3-1-3$ & $/ \mathrm{N} /$ Fruit field & Disperse & White & Round & Smooth & Raised \\
$4-2-2$ & $/ \mathrm{N} /$ Wheat field ${ }^{+}$ & Disperse & White & Round & Smooth & Raised \\
$4-3-3$ & $/ \mathrm{N} /$ Wheat field & Disperse & White & Round & Smooth & Raised \\
\hline \multirow{2}{*}{ Kulu et al. 2015} & Disperse & White & Round & Smooth & Raised \\
\hline
\end{tabular}

/N/ - "Nart" Research and Education Center, /U/- "Unjin" Research and Education Center,

* - no rotation, ${ }^{+}$- fallow field used to wheat and wheat rotation field/, - - fallow field used to no rotation wheat field 
Morphological characterization of $B$. bassiana isolateshave shown the following, as colony color was white and texture was smooth as like powder, and it is identical when colony growth more. Among six isolates, there were no significant differences on color and texture. This result was coincided to Kulu et al. which shown that $B$. bassianawill grow on PDA medium as white mycelium and form white powder layer (Fig. 1, 2).
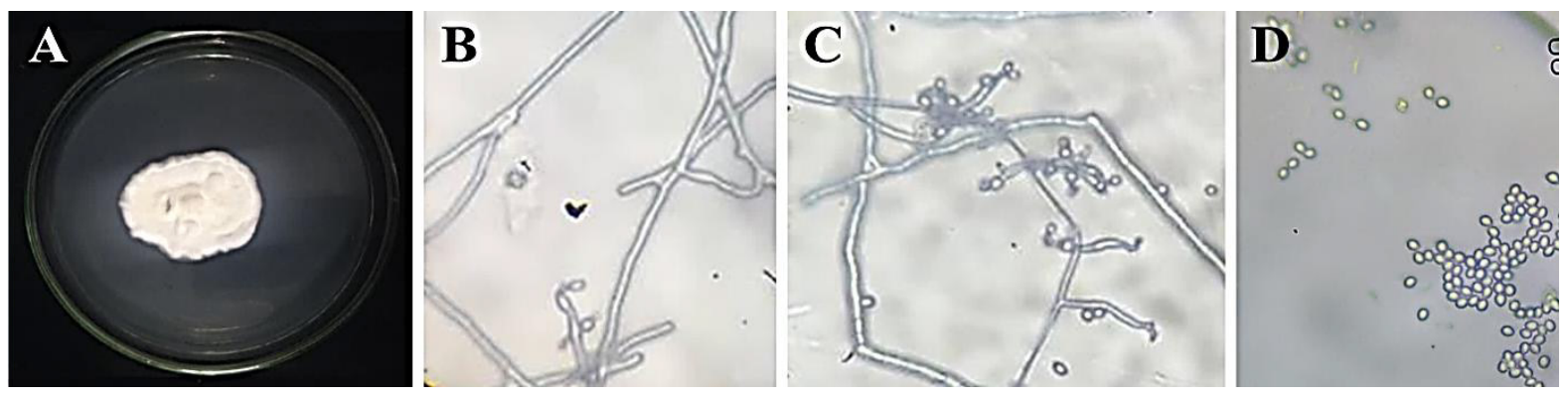

Figure 1. Morphological characterization of B. bassiana isolation.

A) Colony morphology of B. bassiana; B) Mycelium C) Conidia and phialides D) Conidia

Based on microscopic observation, hyphae have branched and formed conidiogene cells, and branch long. Single cell B. bassiana conidium was round and tends to oval.

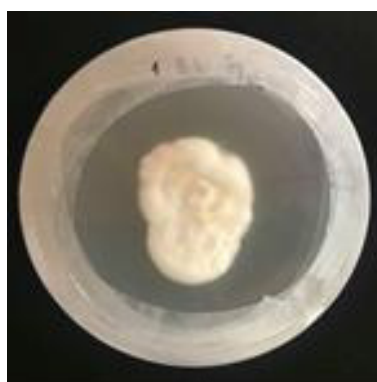

B.b

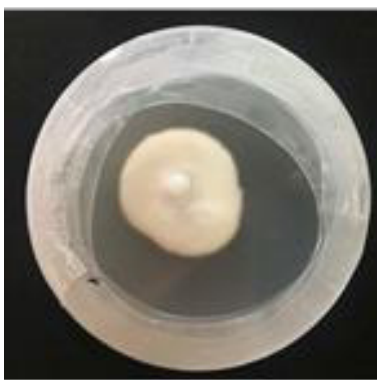

$3-1-3$

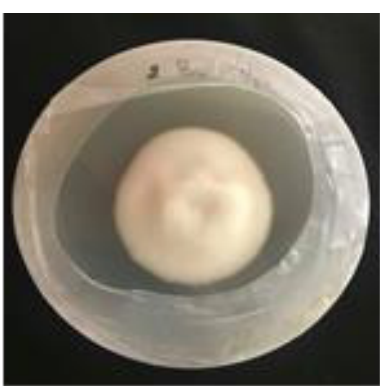

$\mathrm{Bu}$

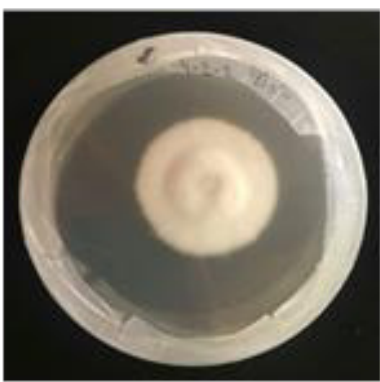

$4-2-2$

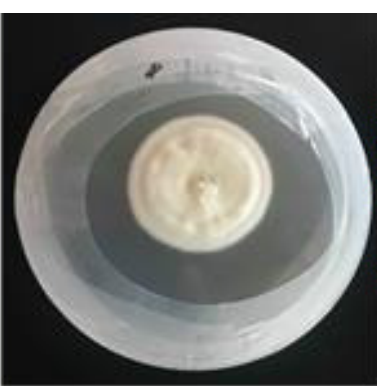

$1-1-3$

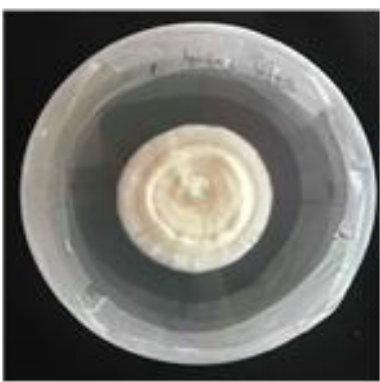

4-3-3

Figure 2. Pure isolations of soil samples taken from different crop fields.

\section{Molecular identification of $B$. bassian in PDAY}

\section{medium after 21 days of culture}

Molecular analysis confirmed the result of morphological identification and it indicated that entomopathogenic fungi $B$. bassiana preserved in soils from fruit and no rotation wheat fields located in Nart, and potato field of Unjin, respectively.

Six fungal isolates located at the same band and were characterized by sequencing of the internal transcribed spacer (ITS) rDNA using ITS1 and IT4 primers (Fig 3). Isolate sequences had 100\% homology to Beauveriabassiana. The nucleotide sequences were deposited in GenBank (KT310219, KR998521, KR998520)

https://www.ncbi.nlm.nih.gov/nuccore/1293835097 


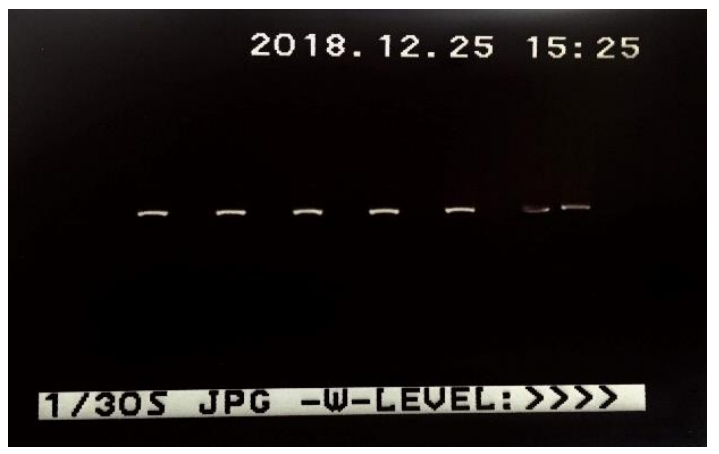

Figure 3. All isolates have same bands on agarose gel 1-B.b, 2-Bu, 3-1.1.3, 4-3.1.3, 5-4.2.2, 6-4.3.3

\section{DISCUSSION}

Based on morphological and molecular characterization of $B$. bassiana found in different crop fields, the results indicate that agricultural soils are an important reservoir of entomopathogenic fungi.

Project on biological control of insects using entomopathogenic fungi must consider the availability and acquisition the cost of virulent strains from germplasm collections [4]. In this aspect, it is important to explore local environments to detect promising, virulent fungal strains. This is the primary

\section{CONCLUSION}

Based on morphological and molecular identification of fungi B. bassiana were found in agricultural soils with different crops. There are no morphological and molecular differences between $B$. bassiana isolates. stage in the development of bio-pesticide for biological management.

Several studies suggest that soil texture, acidity and organic matter content led to progressively higher percentages of entomopathogenic fungi in soils [8]. Quesada-Moraga et al. 2007, concluded that absence and less occurrence of $B$. bassiana due to the less content of organic matter [9].

Therefore, further study focused more about the insect-pathogen dynamics in soils, and ecology of entomopathogenic fungi in different soil types and in different geographical regions are necessary.

Our study indicated that agriculture soils are an important reservoir of entomopathogenic fungi and its potential for using as biological control of pests.

\section{REFERENCES}

[1] IP Kulu, AL Abadi, A Afandhi, N Aidawati, "Morphological and Molecular Identification of Beauveria bassiana as Entomopathogen Agent from Central Kalimantan Peatland, Indonesia", International Journal of ChemTech Research, vol. 8, pp. 2079-2084, 2015

[2] RA Hall, G Zimmermann and A Vey, "Guidelines for the registration of entomogenous fungi as insecticides", Entomophaga, vol.27, pp.121-127, 1982

[3] M Laird, LA Lacey and EW Davidson, "Safety of microbial insecticides". Boca Raton, FL: CRC Press, pp.259, 1990

[4] AA Shahid, AQ Rao, A Bakhsh and T Husnain, "Entomopathogenic fungi as biological controllers: new insights into their virulence and

pathogenicity" Arch. Biol. Sci., vol. 64, pp.2142, 2012, doi 10.2298/abs1201021s

[5] AS Seyed, "Isolation, identification and pathogenicity assessment of a new isolate of entomopathogenic fungus, beauveria bassiana in Iran".Journal of plant protection research, vol. 50, pp.158-163, 2010

[6] B.Oyuntogtokh, D.Dulamjav, M.Otgonzaya, D.Nasanjargal, I.Byambasuren, "Study results on experimenting bioproduct of M.anisopliae g09/22 local strain against eclipophlepsbogdanovisergtarb", Journal of agricultural sciences, Vol 15, pp. 147-151, 2015

[7] Kh.Otgonjargal, "Results of the study on local strain of Entomopathogenic fungus Beauveriabassiana” PhD dissertation, 2011 
[8] S.R.Sanchez-Pena, J.S.J and R.F.Medina, "Occurrence of entomopathogenic fungi from agricultural and natural ecosystems in Saltillo, Mexico, and their virulence towards thrips and white flies". Journal of insect science, vol. 11, pp. 2011, doi: 10.1673/031.011.0101
[9] E.Quesada-Moraga E., Juan A. Navas-Cortés, A.A.Elizabeth Maranhao, A Ortiz-Urquiza, "Factors affecting the occurrence and distribution of entomopathogenic fungi in natural and cultivated soils". Mycological research, vol. 111, pp.947-966, 2007 